SEZEN KORKULU, M.A. ${ }^{1}$

(Corresponding author)

E-mail: sezen.korkulu@logisztika.bme.hu

KRISZTIÁN BÓNA, Ph.D. ${ }^{1}$

E-mail: krisztian.bona@logisztika.bme.hu

${ }^{1}$ Department of Material Handling and Logistics Systems,

Budapest University of Technology and Economics

Bertalan Lajos street 7-9. bdg. L., 1111 Budapest, Hungary
Science in Traffic and Transport Original Scientific Paper Submitted: 16 Mar. 2021 Accepted: 19 Oct. 2021

\title{
DEVELOPMENT OF A LOT-SIZING MODEL TO PREVENT HEAT STRESS AND WORK-RELATED MUSCULOSKELETAL DISORDERS
}

\section{ABSTRACT}

Management of heat stress and metabolic cost is vital for preventing any work-related disorders. In this paper, we integrated rest time formulations for heat strain and metabolic cost to develop a new lot sizing model for preventing heat exposure and work-related musculoskeletal disorders. The effects of heat strain and rest allowance on the total cost of the production supply process were investigated. The problem studied in this paper was the handling of the raw materials placed in boxes by manual material handling in order to supply the material requirement of a production line placed in a production area. For the realisation of the material handling transactions between the raw material warehouse and the production line, Electric Pallet Jack (EPJ) was used. The study covers the investigation of picking, storing, and carrying motions for the manual handling of these materials. The result of the analysis has shown that $8.5 \%$ savings were achieved by using the heat strain and rest time in comparison to the total cost of this part of the production line supply process with the ISO 7243 maximum metabolic work limit. Consequentially, the analysis results showed that the developed method demonstrated the viability of lot sizing model optimisation with multiple objectives and complex constraints with regards to the metabolic cost and heat strain.

\section{KEY WORDS}

ergonomics; manual material handling; metabolic cost; occupational heat stress; rest allowance.

\section{INTRODUCTION}

Many researchers have investigated economic and environmental sustainability of logistics systems [1-6]. Economic and environmental aspects of sustainability in logistics systems have been extensively studied. Inventory models have been extended with economic (time-varying demand, inflation, shortages), environmental ( $\mathrm{CO}_{2}$ emission, environmental cost), and social (human rights, fair labour practices, living conditions, health, and safety) sustainability aspects [7]. The environmental and economic sustainability aspects have particularly been studied extensively [8-10]. According to Korkulu and Bona [11], there are few contributions regarding the social sustainability aspect in the logistics systems [12-25]. Most of the studies have focused on the human energy expenditure as an ergonomic aspect. The heat strain recovery time, and integration of the heat strain recovery and rest time with human energy expenditure as an ergonomic measure has not been studied.

Occupational health and safety is one of the most critical components of socially sustainable logistics systems. Occupational health and safety implement strategies and regulations to prevent occupational and work-related disorders. It has an economic impact as it decreases work-related disorders, which contributes to a reduction in productivity and an increase in medical expenses due to disability compensation. The most common occupational and work-related diseases are work-related musculoskeletal disorders and heat-related diseases. Heat-related diseases are associated with heatstroke, heat exhaustion, heat cramps, heat syncope, heat rash, and rhabdomyolysis [26-28]. Work-related musculoskeletal disorders are sprains, strains, soreness, back disorders, pain, and carpal tunnel syndrome, which are associated with repetitive motion, postures, excessive force, the weight of an object lifted, high static muscle load, and sudden applications of force. According to the last report of the International Labour Organisation (ILO) [29], 2.3 million women and men around the world are subject to work-related diseases every year. The last report of 
the European Agency for Safety and Health at Work [30] has shown that work-related musculoskeletal disorders are one of the most frequent causes of the work-related mortality in the EU-28 (14.66\%) and in the world $(14.96 \%)$. It leads to the total costs of work-related musculoskeletal disorders of up to $2 \%$ of GDP in Europe [31].

We suppose that the ergonomic measures can be effective to prevent work-related musculoskeletal disorders and heat-related diseases with the sizing of the handled lots, which considers ergonomic measures in the material handling process. The investigation of the literature has proved that there are few studies that integrate lot sizing and ergonomics. Particularly, there is no study that integrates both thermal work limit, rest allowance, and metabolic cost. To close this research gap, the paper at hand presents an extension of the ergonomics studies in the lot sizing [16-19] and development of a new lot sizing model. The developed economic and ergonomic lot sizing model integrated a rest allowance formula developed by Price [32], heat strain recovery time formulas presented by Rowlinson and Jia [33] and Brake and Bates [34], and metabolic rate formulas by Garg et. al. [35] for preventing work-related musculoskeletal disorders and heat-related diseases.

This paper is structured as follows: the next section presents a literature review on sustainable logistics systems with ergonomic measures. Section 3 presents the problem in detail and explains the necessary assumptions. Section 4 presents the mathematical formulation of the developed lot sizing model with ergonomic aspects, and Section 5 presents the results of a numerical example and a parameter analysis in the investigated case. Finally, Section 6 concludes the paper.

\section{LITERATURE REVIEW}

In recent years, sustainability aspects in logistics systems have gained attention [36]. Primarily, researchers extensively investigated the economic and environmental aspects of sustainability [7]. However, there are few contributions regarding the social sustainability aspects [11]. Battini et al. [14] have investigated designing the assembly system with ergonomics, and they have found that assessing time efficiency in modern industries design of assembly system and ergonomics should go hand in hand. Battini et al. [16] developed a new measurement technique, and the model helps to simplify the ergonomic assessment of the assembly tasks. Battini et al. [15] developed formulas that considered human availability and rest allowance. Their model proved that improvement in the ergonomic conditions has a positive impact on the total cost of the system. Battini et al. [18] developed a new model for assembly line balancing that integrates energy expenditure rate. Battini et al. [19] developed a mixed-integer model that integrates assembly line balancing and parts feeding and rest allowances. Andriolo et al. [13] developed a lot-sizing model that minimises the cost and the ergonomic risks. Battini et al. [19] developed a mathematical model that investigates two different motions (picking and storing motions) with the metabolic cost for the rest time assessment. Botti et al. [20] developed a model to design lean processes for the hybrid assembly lines with ergonomics. Finco et al. [21] integrated energy expenditure and rest allowance on the heuristic methods for the assembly balancing problem. Gholamian et al. [22] developed a mathematical model that integrated environmental ergonomics and environmental pollution to minimise the cost and the environmental pollution. Finco et al. [23] developed a bi-objective model that eliminates ergonomic risks in the assembly line design with vibration exposure. Al-Araidah et al. [12] developed a Monte Carlo simulation model that considers female order pickers to estimate fatigue allowance [32] with the integration of the energy expenditure formulas of Garg et al. [35]. Finco et al. [22] developed a mathematical model for assembly line balancing problems with the smoothness index, which integrates human energy expenditures as ergonomic aspects. Tang et al. [25] developed a multi-objective mathematical model that eliminates the ergonomic risks for U-shaped assembly lines with the integration of the OCRA method.

As the literature review indicated, there are inventory models mostly with human energy expenditure, OCRA method, and vibration exposure. The research gap can be described as follows: most researchers have focused on the human energy expenditure as an ergonomic aspect and the thermal work limit as an ergonomic aspect has not been studied. Moreover, the lot size of the handling materials in the production line material supply with thermal work limit, rest allowance, and metabolic cost have not been investigated. Therefore, the paper at hand presents the extension of the ergonomics studies in the lot sizing $[16,18,19]$ and the development of a 
new model for determining the lot sizes in the material handling with ergonomic aspects to close this research gap. The developed lot sizing model considers a thermal work limit with rest time and human energy expenditure for preventing the work-related musculoskeletal disorders and heat stress to eliminate the ergonomic risks, and supports economic and social sustainability.

\section{PROBLEM STATEMENT}

The problem studied in this paper is a typical case of a production line supply process. In order to investigate the effects of the ergonomic aspects, the developed model covers and highlights especially the handling of the raw materials stored in boxes manually. The boxes are moved from the Electric Pallet Jack (EPJ) to a flow-rack. The boxes are handled during the presented process by manual material handling with picking, storing, and carrying motions when the logistics operator refills the supermarket.

The supermarket expression is a specific definition of the storage equipment used in the lean production systems and it is installed in the production area for supporting the storage of the main components (i.e., raw materials, auxiliary materials) that must be used in the assembly process of the finished products. In most cases, this equipment can be defined as a traditional flow rack system which is suitable to store specific boxes where the materials are placed. This storage system can be served manually by using logistics or production operators, and it can be very useful in cases where predefined quantities of stock must not be held too far from the production lines. Using this opportunity, the stock can be easily reachable with high availability and not too large operation time, and it is located next to the production line (see Figure 1).

The high-level process flow can be seen in Figure 2 and the investigated part of the process is denoted with a dashed line and in light grey colour.

In the model, the order picking activities and the preparation and kitting processes in the raw material warehouse have not been investigated because they are defined as a connected logistics subsystem. The transportation of the prepared raw materials stored in the boxes from the warehouse with the use of EPJ was not considered in the model because there is no such physical activity in ergonomic terms that must be realised during this sub-process. Therefore, the effect and the investigation of the pushing motion associated with transportation of the EPJ from the

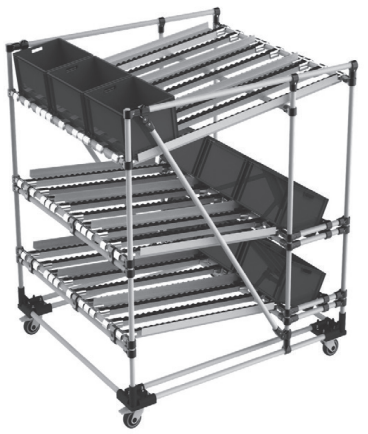

Figure 1 - The representation of supermarket

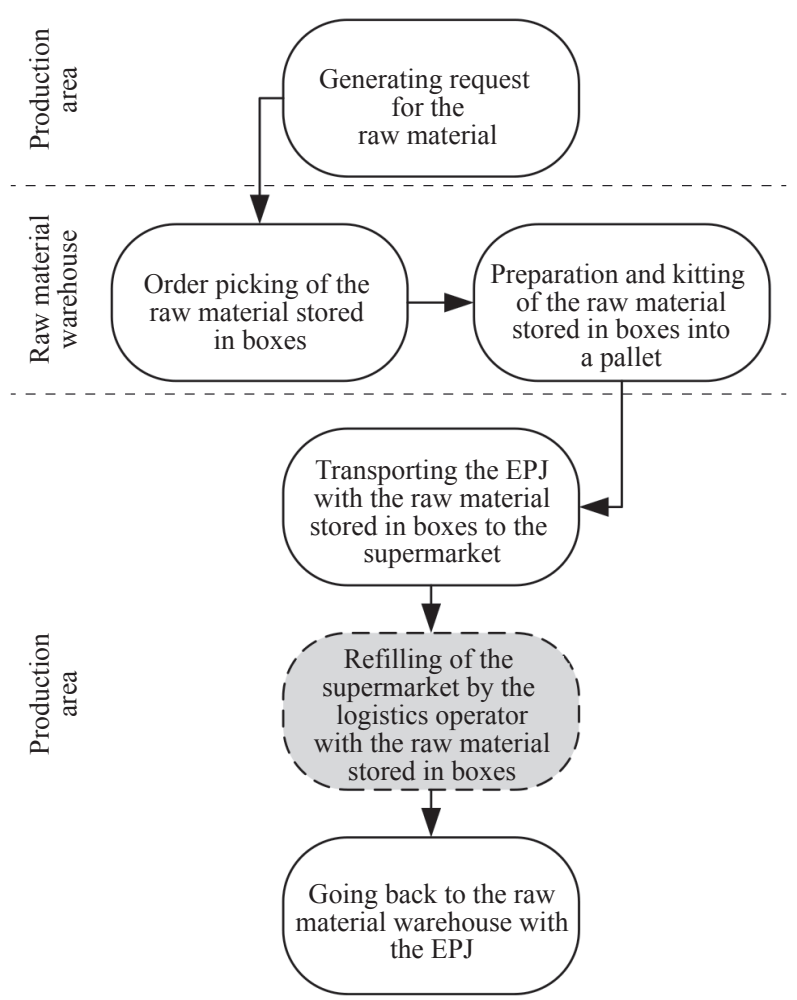

Figure 2 - The "high-level" process flow of the production line supply process

warehouse can also be eliminated. This thesis can also be mentioned regarding the case of the going back activity to the raw material warehouse with the EPJ. The systematic layout of the examined physical process can be defined in Figure 3, and the examined subsystem is denoted with a dashed line and in light grey colour.

The investigated job cycle consists of picking raw materials from the EPJ, carrying the raw materials to the supermarket of the production line, storing raw materials into the supermarket, and walking back to the EPJ (see Figure 4). As the study investigates the "light" work, the job cycle starts with the picking of the raw materials from the EPJ. 


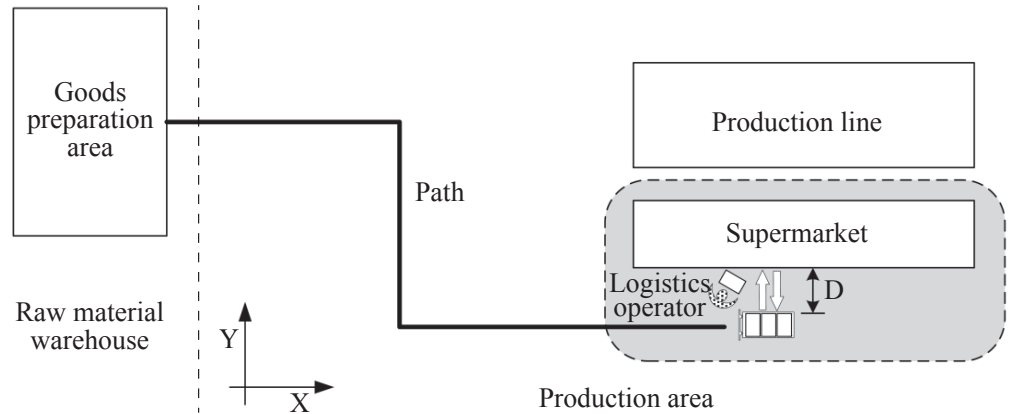

Figure 3 - The high-level systematic layout of the investigated

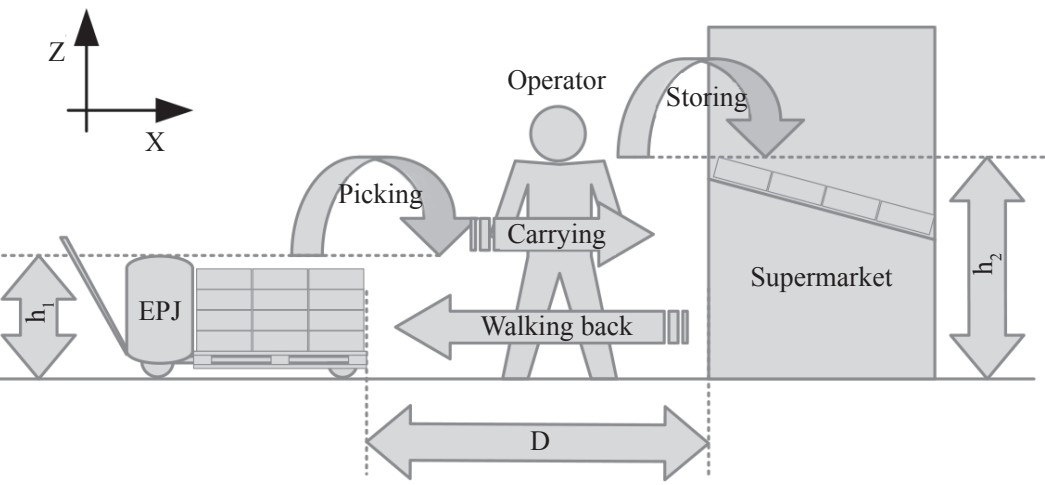

Figure 4 - The examined job cycle

As it can be seen in the figure, $h_{1}$ is the vertical height from floor $(\mathrm{m})$ in the case of the picking activity, and $h_{2}$ is the vertical height from the floor (m) in the case of the storing activity. It can be supposed that the $D$ distance between the EPJ and the supermarket can be defined as between 1 and 3 meters because the EPJ can be stopped near the supermarket.

The following further assumptions were made for developing the model.

The developed model investigates supplying one kind of raw material with one operator to the production line as a Single-Operator-Single-Material (SMSO) model. Therefore, the model considers only a single type of raw material. The developed model covers the rest allowance formula of Price [32], which suggests that rest time is necessary if the mean work rate is higher than $300 \mathrm{~W}$, i.e., light to moderate work according to ISO 7243 [37]. Therefore, light to moderate work metabolic cost is considered in the model to calculate the heat strain recovery time.

\section{MATHEMATICAL MODEL}

\subsection{Application of the rest allowance}

Rest allowance is scheduled break time planned to allow a worker to retrieve from fatigue. Thus, planned rest allowance is crucial to prevent work-re- lated disorders [38]. To prevent work-related musculoskeletal disorders and heat-related illness, we integrated the rest allowance equation based on metabolic cost presented by Price [32] and heat strain recovery time formulas presented by Rowlinson and Jia [33] and Brake and Bates [39] into the lot sizing model.

Recovery time of the heat strain presented by Rowlinson and Jia [33] and Brake and Bates [39] can be defined as follows:

$M_{\text {work }} \cdot t_{\text {work }}+M_{\text {rest }} \cdot t_{\text {rest }}=L M R \cdot\left(t_{\text {work }}+t_{\text {rest }}\right)$

where $M_{\text {work }}$ is the metabolic rate of work, $M_{\text {rest }}$ is the metabolic rate of rest, $t_{\text {work }}$ is the total time needed for the investigated operation, $t_{\text {rest }}$ is the total resting time and $L M R$ is the Limiting Metabolic Rate for the continuous work. By adjusting the Equation 1 by $M_{\text {work }}=M W R$ (Mean Work Rate), the following equation can be written:

$$
\begin{aligned}
& \operatorname{MWR}(q) \cdot t_{\text {work }}(q)+M_{\text {rest }} \cdot T_{\text {heat rest }}(q) \\
& =L M R \cdot\left(t_{\text {work }}(q)+T_{\text {heat rest }}(q)\right) \\
& T_{\text {heat rest }}(q)=\frac{L M R \cdot t_{\text {work }}(q)-M W R(q) \cdot t_{\text {work }}(q)}{M_{\text {rest }}-L M R}
\end{aligned}
$$

It can be seen that some parameters in the Equation 3 will strongly depend on the lot size (noted as $q$ ), and this dependence will be denoted with $q$ in the following. In the Equation 2 the $T_{\text {heat rest }}(q)$ 
is the rest time for preventing ergonomic risks that occur from heat strain. $M_{\text {rest }}$ is $55 \mathrm{~W} / \mathrm{m}^{2}$ which equals $99 \mathrm{~W}$ (rest metabolic rate converted from $\mathrm{W} / \mathrm{m}^{2}$ to $\mathrm{W}$ assuming a body surface area of $1.8 \mathrm{~m}^{2}$ ) as suggested by the ISO 8996 [40]. LMR is 165 $\mathrm{W} / \mathrm{m}^{2}$ which equals $297 \mathrm{~W}$ for moderate work in the case of sustainable continuous work with a threshold value (WBGT $-{ }^{\circ} \mathrm{C}$ ) $28^{\circ} \mathrm{C}$ as suggested by the ISO 7243 [31].

The rest allowance equation based on the metabolic cost presented by Price [32] can be defined as follows:

$$
\begin{aligned}
& T_{\text {rest }}(q)=\frac{M W R(q)-300}{300-R R} \cdot t_{\text {work }}(q), \\
& \text { if } M W R(q)>300 \mathrm{~W}, \text { else } T_{\text {rest }}(q)=0 \\
& \text { where, } \\
& t_{\text {work }}(q)=t_{p}(q)+t_{s}(q)+t_{c}(q)+t_{w b} \\
& M W R(q)= \\
& \frac{M_{p}(q) \cdot t_{p}(q)+M_{s}(q) \cdot t_{s}(q)+M_{c}(q) \cdot t_{c}(q)+M_{w b} \cdot t_{w b}}{t_{p}(q)+t_{s}(q)+t_{c}(q)+t_{w b}} \cdot 69.77
\end{aligned}
$$

where $R R$ is the relaxation rate, $t_{p}(q)$ is the picking time of the handled unit (i.e., a box) from the EPJ, $t_{s}(q)$ is the storing time of the handled unit into the supermarket of the production line, $t_{c}(q)$ is the carrying time of the handled unit, $t_{w b}$ is the time of walking back to the EPJ after storing the unit into the supermarket, $M_{p}$ is the metabolic rate of the picking, $M_{s}$ is the metabolic rate of the storing, $M_{c}$ is the metabolic rate of the carrying, and $M_{w b}$ is the metabolic rate of the walking back activity.

We estimated the above-mentioned main components of the total time needed of the operation based on a $y=A \cdot x^{B}$ power regression model (see Figure 5), where the A and B parameters have been estimated based on the methodology of the AIM. AIM [41] is an abbreviation which means "Anyagmozgatási Időszükséglet Meghatározás" in Hungarian developed by Hungarian researchers in mid1960s, and it can be translated as Determination of Time Needed for Material Handling. So, AIM is a table-based method for supporting the calculation of the time necessities of the material handling using predefined time constants, which values can be found predefined in the specific tables of the AIM (See Table 1 below).

Based on the methodology of the AIM, the different time components have been estimated in the case of different $w(q)=q \cdot w_{u}$ values, where $w_{u}$ is the unit weight of the handled raw material in kilograms, and $w(q)$ is the estimated weight of the handled unit load (i.e., a box) in kilograms. After the calculation of these values, we applied the above-mentioned

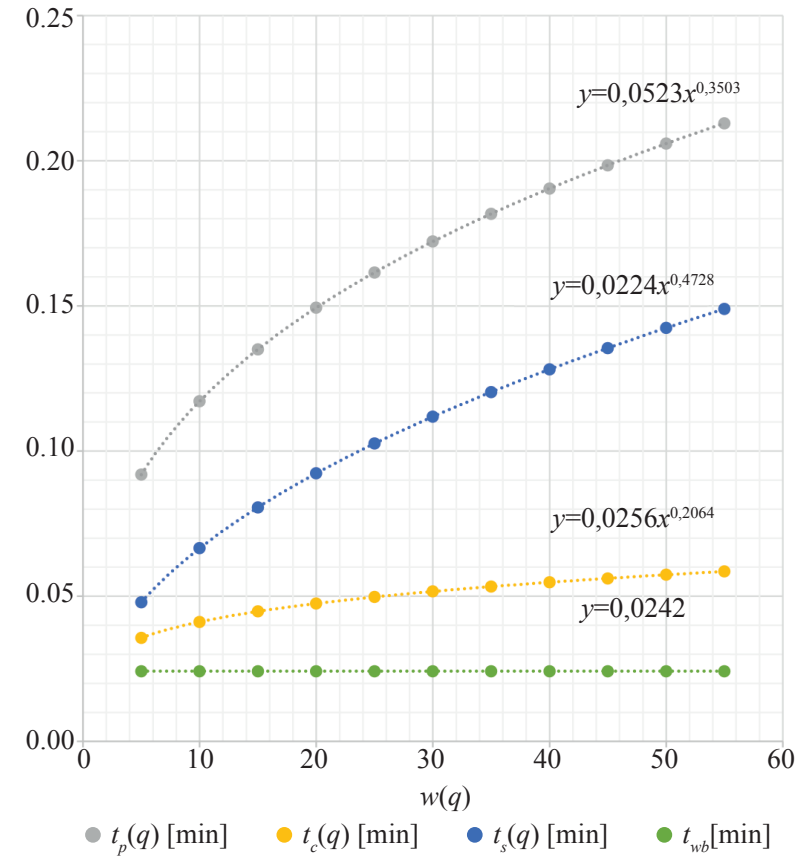

Figure 5 - The power regression estimation function of the time needed based on the AIM tables

power regression to determine the suitable function for the estimation of the time needed for the applied components of the operation. The results can be seen in Figure 5, and the equations can be written as follows:

$t_{p}(q)=0.0523 \cdot w(q)^{0.3503} R^{2}=0.8532$

$t_{c}(q)=0.0256 \cdot w(q)^{0.2064} R^{2}=0.8522$

$t_{s}(q)=0.0224 \cdot w(q)^{0.4728} R^{2}=0.8952$

The time needed for walking back $\left(t_{w b}\right)$ to the EPJ is constant and does not depend on the lot size. Furthermore, in Figure 6 the estimation function of the total time needed for the operation can be seen.

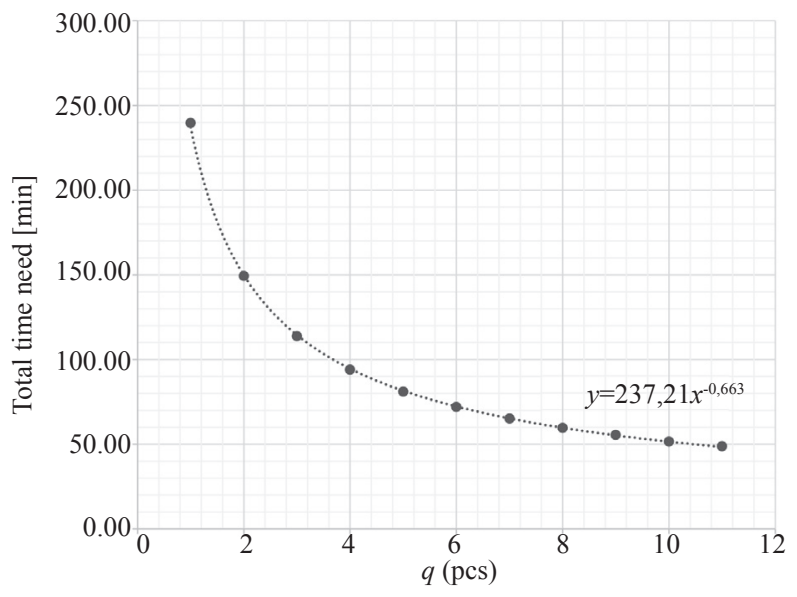

Figure 6-The total time needed in the function of the lot size 
Table 1 - The applied parts of the AIM tables

Time needed for manual material handling

\begin{tabular}{|c|c|c|}
\hline \multicolumn{2}{|c|}{ Unit weight [kg] } & \multirow{2}{*}{$\begin{array}{c}\text { Weight } \\
\text { code }\end{array}$} \\
\hline From & To & \\
\hline 0.00 & 2.00 & 1 \\
\hline 2.01 & 5.00 & 2 \\
\hline 5.01 & 20.00 & 3 \\
\hline 20.01 & 50.00 & 4 \\
\hline
\end{tabular}

\begin{tabular}{|c|c|}
\hline \multicolumn{2}{|c|}{$\begin{array}{r}\text { Time need of movement } \\
{\left[10^{-2} \mathrm{~min} / \mathrm{m}\right]}\end{array}$} \\
\hline 1 & 1.10 \\
\hline 2 & 1.40 \\
\hline 3 & 1.70 \\
\hline 4 & 2.00 \\
\hline
\end{tabular}

\begin{tabular}{|c|c|c|}
\hline \multicolumn{2}{|c|}{ Height of picking up / storing [m] } & \multirow{2}{*}{$\begin{array}{c}\text { Height } \\
\text { code }\end{array}$} \\
\hline From & To & \\
\hline 0.00 & 0.70 & 1 \\
\hline 0.71 & 1.40 & 2 \\
\hline 1.41 & 2.10 & 3 \\
\hline
\end{tabular}

\begin{tabular}{|c|c|c|c|c|c|}
\hline \multicolumn{6}{|c|}{ Time need of picking up $\left[10^{-2} \mathrm{~min}\right]$} \\
\hline & 1 & 2 & 3 & 4 & 5 \\
\hline 1 & 8 & 10 & 11 & 15 & 16 \\
\hline 2 & 6 & 8 & 10 & 13 & 14 \\
\hline 3 & 10 & 12 & 13 & 15 & 17 \\
\hline
\end{tabular}

\begin{tabular}{|c|c|c|}
\hline \multicolumn{2}{|c|}{ Unit weight $[\mathrm{kg}]$} & \multirow{2}{*}{$\begin{array}{c}\text { Weight } \\
\text { code }\end{array}$} \\
\hline From & To & 1 \\
\hline 0.00 & 10.00 & 2 \\
\hline 10.00 & 20.00 & 3 \\
\hline 20.00 & 30.00 & 4 \\
\hline 30.00 & 40.00 & 5 \\
\hline 40.00 & 50.00 & \\
\hline
\end{tabular}

\begin{tabular}{|c|c|c|c|c|c|}
\hline \multicolumn{6}{|c|}{ Time need of storing $\left[10^{-2} \mathrm{~min}\right]$} \\
\hline & 1 & 2 & 3 & 4 & 5 \\
\hline 1 & 6 & 7 & 8 & 11 & 12 \\
\hline 2 & 4 & 6 & 8 & 9 & 11 \\
\hline 3 & 8 & 9 & 10 & 11 & 12 \\
\hline
\end{tabular}

\begin{tabular}{|c|c|c|}
\hline \multicolumn{2}{|c|}{ Unit weight $[\mathrm{kg}]$} & \multirow{2}{*}{$\begin{array}{c}\text { Weight } \\
\text { code }\end{array}$} \\
\hline From & To & 1 \\
\hline 0.00 & 2 & 2 \\
\hline 2.01 & 5 & 3 \\
\hline 5.01 & 20 & 4 \\
\hline 20.01 & 50 & \\
\hline
\end{tabular}

\begin{tabular}{|c|c|}
\hline \multicolumn{2}{|c|}{ Additional factor } \\
\hline 1 & 0.1 \\
\hline 2 & 0.15 \\
\hline 3 & 0.25 \\
\hline 4 & 0.35 \\
\hline
\end{tabular}

$M_{p}(q)=\frac{0.01 \cdot\left[0.514 \cdot B W \cdot\left(0.81-h_{1}\right)+(2.19+0.62 \cdot S \cdot w(q)) \cdot\left(h_{2}-h_{1}\right)\right]}{t_{p}(q)}$ for $h_{1}<h_{2} \leq 0.81$

$M_{s}(q)=\frac{0.01 \cdot\left[0.511 \cdot B W \cdot\left(0.81-h_{1}\right)+0.701 \cdot w(q) \cdot\left(h_{2}-h_{1}\right)\right]}{t_{s}(q)}$ for $h_{1}<h_{2} \leq 0.81$

$M_{c}(q)=\frac{0.01 \cdot\left[\left(80+2.43 \cdot B W \cdot V^{2}+4.63 \cdot w(q) \cdot V^{2}+4.62 \cdot w(q)+0.379 \cdot(w(q)+B W) \cdot G \cdot V\right) \cdot t_{c}(q)\right]}{t_{c}(q)}$

$M_{w b}=\frac{0.01 \cdot\left[\left(51+2.54 \cdot B W \cdot V^{2}+0.379 \cdot B W \cdot G \cdot V\right) \cdot t_{w b}\right]}{t_{w b}}$

To express the mean work rate in Watt, MWR will be multiplied with $1 \mathrm{Watt}=69.77 \mathrm{kcal} / \mathrm{min}$ as suggested by the ISO 80000-5 [42]. MWR is calculated with the metabolic rate equations ( $\mathrm{kcal} / \mathrm{min})$ presented by Garg et al. [35] (Equations 10-13) where $B W$ is the body weight in kilograms, $V$ is the speed of walking in $\mathrm{m} / \mathrm{s}, G$ is the grade of the walking surface, $S$ is a decision variable based on the gender of the worker $(\mathrm{M} / \mathrm{F}=1 / 0)$.

Finally, the total rest time can then be defined as follows:

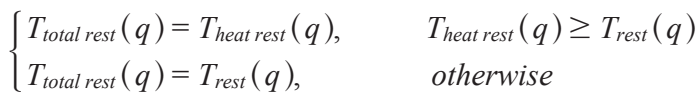

\subsection{The mathematical description of the total cost function}

In the presented model we only investigated the inventories in the production area, especially in the central supermarket, where the materials for the continuous line supply must be handled in order to ensure continuous production. We focused mainly on the physical side of the line supplying process, and we integrated an important aspect into the investigation of the value-creating process which is ergonomics. The materials needed for the realisation of the production activities can reserve a huge space in the production area which can be interpreted as waste and leads to high costs. Because of 
this, there are other methodologies that try to support the reaching of the minimal space needed in the line supply, for example, with the application of the pull-principle (see the methods of lean thinking), which can be advantageous in terms of the ergonomic aspects, but these applications also result in smaller lot sizes. However, in order to make the correct decision and decrease the ergonomic risks, the ergonomic aspects must also be investigated. Our aim was to build a model which is similar to the traditional inventory models because this phenomenon in the production lines is very similar to an inventory process, where stock must be held near to the production line somewhere in a supermarket or directly integrated into the line where these materials will reserve the valuable spaces instead of ensuring a place for realising any production activity. In this way, our aim was to describe this phenomenon in a total cost model where the cost of the stock holding will be used as the cost of the space reservation. Additionally, it must be mentioned that the specific cost of the realisation of the line supplying transactions must also be investigated, which will be described in the cost of the material handling transactions where the ergonomic aspects can be integrated as well. As a first step, we investigated a typical physical line supply activity to discover the possibilities in this direction in the case of a "Single Material and Single Operator (SMSO)" model.

As the raw material requirement of the production line is quasi constant, which means that no fluctuation in the time and in the quantity dimension of the raw material usage can be defined, then the inventory process realised in the supermarket can be described with the following simple sawtooth diagram (see Figure 7).

In this diagram, the $t$ parameter means the socalled "availability time". In this interval, the material can be available to fulfill the material requirements of the production line. The maximum stock in the supermarket will be $q$, which is equal to the applied lot size, and $q / 2$ average stock must be held in the supermarket to ensure continuous production. Consequently, if the frequency of refilling is higher, then the average stock level will be lower. If the frequency of the refilling is lower, then the average stock level will be higher, and in this case, a larger supermarket must be planned next to the production line, and more space must be reserved in the production area, which is not too favourable in terms of the production. Additionally, the ergonomic aspect

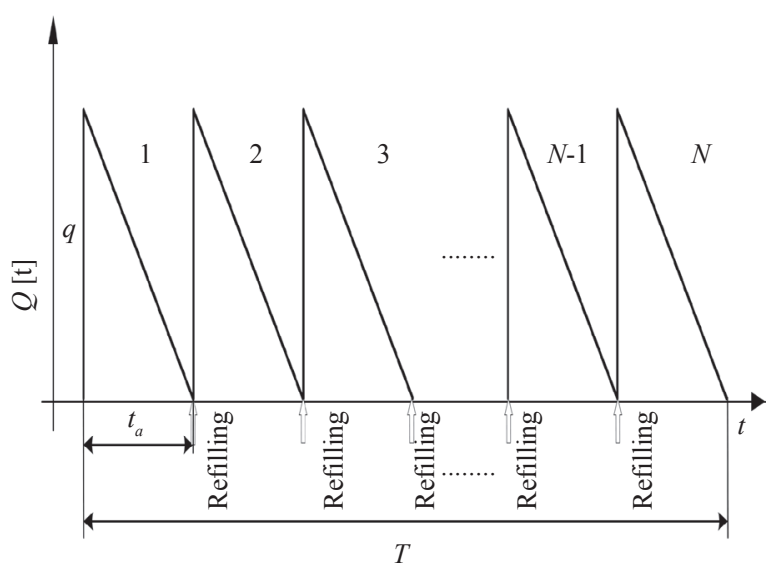

Figure 7 -Changing of the stock level in the supermarket

can be integrated here, which can be one of the most significant aspects of this trade-off situation, in addition to other problems of the logistics operation that need to be handled.

Therefore, we interpreted the main cost components based on the above-presented problem description, and we extended and developed the existing studies in literature of Battini et al. $[18,19]$ with components beside on the cost of operation and cost of rest time with the cost function of the stock holding:

$$
\begin{aligned}
& C_{o}(q)=\left(C_{p}(q)+C_{s}(q)+C_{c}(q)+C_{w b}\right) \\
& =\left(t_{p}(q)+t_{s}(q)+t_{c}(q)+t_{w b}\right) \cdot c_{w} \cdot\left\lceil\frac{Q}{q}\right\rceil
\end{aligned}
$$

where,

$$
\begin{aligned}
& C_{p}(q)=t_{p}(q) \cdot c_{w} \cdot\left\lceil\frac{Q}{q}\right\rceil \\
& C_{s}(q)=t_{s}(q) \cdot c_{w} \cdot\left\lceil\frac{Q}{q}\right\rceil \\
& C_{c}(q)=t_{c}(q) \cdot c_{w} \cdot\left\lceil\frac{Q}{q}\right\rceil \\
& C_{w b}(q)=t_{w b} \cdot c_{w} \cdot\left\lceil\frac{Q}{q}\right\rceil \\
& C_{i}(q)=\frac{t_{a} \cdot q}{2} \cdot\left\lceil\frac{Q}{q}\right\rceil c_{h}=\frac{t_{a} \cdot q}{2} \cdot\left\lceil\frac{T}{t_{a}}\right\rceil \cdot c_{h} \\
& =\frac{t_{a} \cdot Q}{2} \cdot c_{h}=\frac{q \cdot T}{2} \cdot c_{h} \\
& C_{r}(q)=T_{\text {total rest }}(q) \cdot c_{w} \cdot\left\lceil\frac{Q}{q}\right\rceil
\end{aligned}
$$

where $C_{p}(q)$ is the cost of picking, $C_{s}(q)$ is the cost of storing, $C_{c}(q)$ is the cost of carrying, and $C_{w b}$ is the cost of walking back. $C_{o}(q)$ is the total cost of the operation, which includes the picking, storing, and carrying cost of the operation calculated with the total time needed for the operation and using the specific cost of the worker wage $\left(c_{w}\right)$ which is the 
way to calculate the ergonomical risks effect on total cost of the operation based on the study of Battini et al. [19]. $C_{i}(q)$ is the total inventory holding cost calculated with the availability time of the stock in the production line $\left(t_{a}\right)$ and using the specific cost of the stock holding $\left(c_{h}\right)$. Finally, $C_{r}(q)$ is the total rest time cost calculated with the total rest time for preventing ergonomic risks that occur from the heat strain and metabolic cost and using the specific cost of the worker wage $\left(c_{w}\right)$. In any case, it can be supposed that the total number of cycles needed for handling the total $Q$ request of the production line in the case of the investigated raw material can be estimated with $\left\lceil\frac{Q}{q}\right\rceil$ or $\left\lceil\frac{T}{t_{a}}\right\rceil$.

The objective function of the $C(q)$ total cost can be defined as follows:

$$
\begin{aligned}
& C(q)=\left(t_{p}(q)+t_{s}(q)+t_{c}(q)+t_{w b}\right) \cdot c_{w} \cdot\left\lceil\frac{Q}{q}\right\rceil \\
& +\frac{q \cdot T}{2} \cdot c_{h}+T_{\text {total rest }}(q) \cdot\left\lceil\frac{Q}{q}\right\rceil \cdot c_{w}
\end{aligned}
$$

We integrated the heat strain recovery time cost and metabolic cost, as it is a manual material handling process that is a human activity. In this way, it becomes possible to decrease the heat-related and work-related musculoskeletal disorders risk of the logistics operator. The rest times are based on the metabolic cost or metabolic rate of the operator, which is the body's energy expenditure per unit of time for the chosen motion, such as picking, storing, and carrying. It can be said that the optimum solution calculated using this objective function is based on both minimising the ergonomic risk and the total cost of the process. As the model considers two different rest allowance formulas which are aimed to prevent work-related musculoskeletal disorders and heat-related disorders, there are two different total cost formulas for the optimal lot size based on the rest allowances.

Firstly, if $T_{\text {heat rest }}(q)>T_{\text {rest }}(q)$ then the total rest allowance equals $T_{\text {total rest }}(q)=T_{\text {heat rest }}(q)$. In this case, the total cost function could be written as Equation 23.
In the second case, if $T_{\text {heat rest }}(q) \leq T_{\text {rest }}(q)$ then the total rest time will be equal to $T_{\text {total rest }}(q)=T_{\text {rest }}(q)$. The total cost function of this case could be written as Equation 24.

To find the optimum lot size $\left(q^{*}\right)$, where the total cost $(C(q))$ will be minimum, we use the following formal enumeration algorithm for discrete $q$ values, where $q_{\max }=\left\lfloor\frac{360}{M W R}\right\rfloor$ based on the maximum metabolic rate limit $\left(200 \mathrm{~W} / \mathrm{m}^{2}\right)$ for light to moderate work according to the ISO 7243 [37] Hot Environments - Estimation of the heat stress on working man, based on the WBGT-index where MWR equals $360 \mathrm{~W}$.

For $q=1$ to $q_{\max }$

If $T_{\text {heat rest }}(q)>T_{\text {rest }}(q)$ then $T_{\text {total rest }}(q)=T_{\text {heat rest }}(q)$

Calculation of $T_{\text {heat rest }}(q)$

If $M W R(q) \geq L M R$ then calculation of $T_{\text {heat rest }}(q)$ else $T_{\text {heat rest }}(q)=0$

If $T_{\text {heat rest }}(q) \leq T_{\text {rest }}(q)$ then $T_{\text {total rest }}(q)=T_{\text {rest }}(q)$

Calculation of $T_{\text {rest }}(q)$

If $M W R(q) \geq 300 \mathrm{~W}$ then calculation of $T_{\text {rest }}(q)$ else $T_{\text {rest }}(q)=0$

Calculation of $C(q)=C_{o}(q)+C_{i}(q)+C_{r}(q)$

If $C(q)<\operatorname{Min}(C(q))$ then

$\operatorname{Min}(C(q))=C(q)$

$q^{*}=q$

Next $q$

\section{RESULTS AND DISCUSSION}

\subsection{Numerical example}

We apply a numerical illustration where $Q$ equals 1200 pcs, $L M R$ equals $297 \mathrm{~W}, R R$ for standing equals $130 \mathrm{~W}$ [32], $c_{h}$ equals $0.05 \$ / \mathrm{pcs} / \mathrm{h}, c_{w}$ equals $18 \$ / \mathrm{h}$, $B W$ equals $80 \mathrm{~kg}, S$ equals $1, G$ equals $5 \%, T$ equals $480 \mathrm{~min}, V$ equals $1 \mathrm{~m} / \mathrm{s}, h_{1}$ is $0.4 \mathrm{~m}, h_{2}$ is $0.8 \mathrm{~m}$ and $w_{u}$ is $6 \mathrm{~kg}$. The model we examined considers the moderate work, which has $L M R$ equal to $297 \mathrm{~W}$ for moderate work for sustainable continuous work of the heat strain, and it is less than $300 \mathrm{~W}$ which is the limit value of the rest allowance equation of the metabolic cost. Thus, it is the case of $T_{\text {heat rest }}(q)>T_{\text {rest }}(q)$ and $T_{\text {total rest }}(q)=T_{\text {heat rest }}(q)$. The total cost of operation is $C(q)=\$ 17.82$ where the rest time cost equals $C_{r}(q)=0$ for preventing any ergonomic risks regarding heat strain and extreme energy expenditure,

$$
\begin{aligned}
& C(q)=\left(t_{p}(q)+t_{s}(q)+t_{c}(q)+t_{w b}\right) \cdot c_{w} \cdot\left[\frac{Q}{q}\right]+\frac{q \cdot T}{2} \cdot c_{h} \\
& +\left(\frac{\left(M_{p}(q) \cdot t_{p}(q)+M_{s}(q) \cdot t_{s}(q)+M_{c}(q) \cdot t_{c}(q) M_{w b} \cdot t_{w b}\right) \cdot 69.77-L M R \cdot\left(t_{p}(q)+t_{s}(q)+t_{c}(q)+t_{w b}\right)}{L M R-M_{r e s t}}\right) \cdot\left[\frac{Q}{q}\right] \cdot c_{w} \\
& C(q)=\left(t_{p}(q)+t_{s}(q)+t_{c}(q)+t_{w b}\right) \cdot c_{w} \cdot\left[\frac{Q}{q}\right]+\frac{q \cdot T}{2} \cdot c_{h} \\
& +\left(\frac{\left(M_{p}(q) \cdot t_{p}(q)+M_{s}(q) \cdot t_{s}(q)+M_{c}(q) \cdot t_{c}(q) M_{w b} \cdot t_{w b}\right) \cdot 69.77-300 \cdot\left(t_{p}(q)+t_{s}(q)+t_{c}(q)+t_{w b}\right)}{300-R R}\right) \cdot\left[\frac{Q}{q}\right] \cdot c_{w}
\end{aligned}
$$


and the ergonomic lot size $q^{*}=8$ pcs. We calculated the total cost of the maximum metabolic rate limit $\left(200 \mathrm{~W} / \mathrm{m}^{2}\right)$ for light to moderate work according to the ISO 7243 Hot Environments - Estimation of the heat stress on working man [37], based on the WBGT-index, where MWR equals $360 \mathrm{~W}$ for the production supply process under study. According to this limit, the lot size $q=11$. The total cost $\mathrm{C}(q)=\$ 19.48$ and $C_{r}(q)=\$ 4.27$. The saving of our model from using the ergonomic rest time for heat strain and work-related musculoskeletal disorders with metabolic cost equals $8.5 \%$ which is calculated based on the comparison to the total cost of the production supply process under study with the application of the ISO 7243 [37] maximum metabolic work limits.

\subsection{Parameter analysis}

We applied different parameter values to analyse the flexibility of our model for different industrial practices and circumstances. As can be seen in Figure 8, we applied different lot sizes where $w_{u}$ is 5 $\mathrm{kg}, Q$ equals $1200 \mathrm{pcs}, L M R$ equals $297 \mathrm{~W}, R R$ for standing equals $130 \mathrm{~W}$ [32], $c_{h}$ equals $0.05 \$ / \mathrm{pcs} / \mathrm{h}$, $c_{w}$ equals $18 \$ / \mathrm{h}, B W$ equals $75 \mathrm{~kg}, S$ equals $1, G$ equals $5 \%, V$ equals $1 \mathrm{~m} / \mathrm{s}, h_{1}$ is $0.4 \mathrm{~m}$, and $h_{2}$ is $0.8 \mathrm{~m}$ to analyse the effect on the costs of the operation, the inventory cost, the rest time cost, and the total cost.

The results show that the increase in the lot size will lead to an increase in the rest time cost because the higher the $\mathrm{kg}$ value of the load, the higher the rest time necessary for preventing the ergonomic risks. On the other hand, the increase in the lot size will

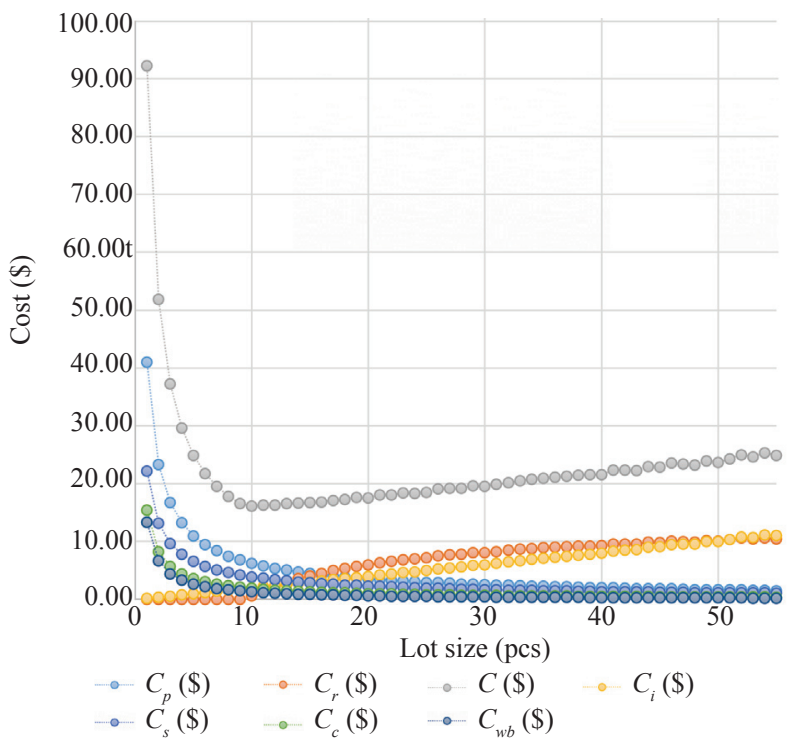

Figure 8-Cost curves for alternative lot sizes where the weight of the item is $5 \mathrm{~kg}$ lead to the decrease of the operational cost for the picking, storing, and carrying motions, and an increase in the inventory cost as it increases the stock on the production line.

We calculated the savings gained by using our approach for different weights of the item. The calculation of the savings based on the comparison of our model and the total cost of the maximum metabolic rate limit $\left(200 \mathrm{~W} / \mathrm{m}^{2}\right)$ for light to moderate work according to ISO 7243 Hot Environments - Estimation of the heat stress on working man [37], based on the WBGT-index values. As can be seen in Figure 9, our new model has higher or lower savings compared to the maximum metabolic rate limit $\left(200 \mathrm{~W} / \mathrm{m}^{2}\right)$ for light to moderate work results.

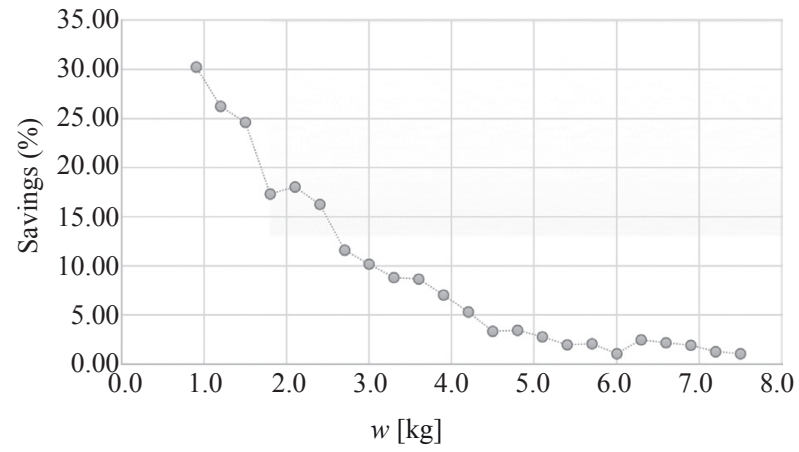

Figure 9 - Savings in the case of different weights of the item

We applied different weights of the item, which changes between 0.9 and 9 in step $0.3 \mathrm{~kg}$, to understand the effect of the weight of the item on the lot size.

The higher item weight leads to smaller optimal lot size as it increases the $\mathrm{kg}$ value of handled unit load (see Figure 10). Therefore, we need to decrease

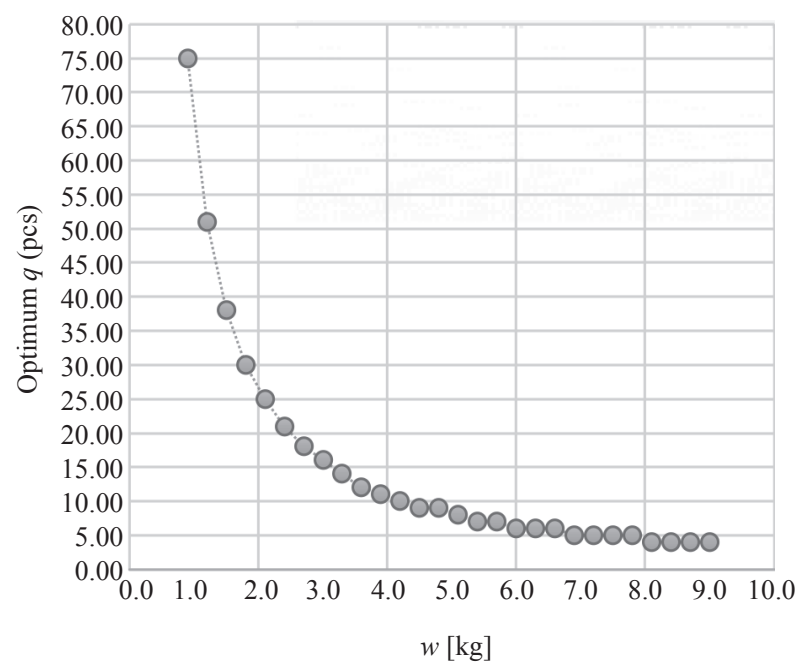

Figure 10-Optimal lot sizes for different weights of the item 


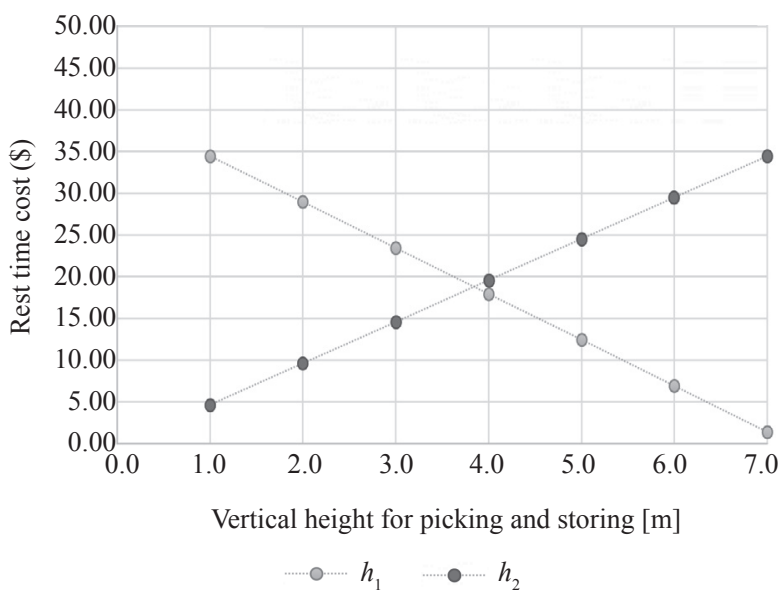

Figure 11 - Rest time cost for different vertical heights of picking and storing

the $\mathrm{kg}$ value of the unit load or, for a heavier load, decrease the lot size to prevent any ergonomic risks from extreme energy expenditure and heat strain.

We applied different vertical heights $\left(h_{1}, h_{2}\right)$ for the picking and storing motions to calculate the effect on the rest time of the operator. The $h_{1}$ and $h_{2}$ changed between 0.1 to $0.7 \mathrm{~m}$ where $h_{1}<h_{2} \leq 0.81$ constraint is considered and $w_{u}$ is $10 \mathrm{~kg}, Q$ equals 2400 pcs, $L M R$ equals $297 \mathrm{~W}, R R$ for standing equals $130 \mathrm{~W}$ [32], $c_{h}$ equals $0.05 \$ / \mathrm{pcs} / \mathrm{h}, c_{w}$ equals $18 \$ / \mathrm{h}, S$ equals $1, G$ equals $5 \%, V$ equals $1 \mathrm{~m} / \mathrm{s}$, and $B W$ is $75 \mathrm{~kg}$.

As can be seen in Figure 11, higher vertical height lowers the rest time requirement in the case of the $h_{1}$ parameter, which is the vertical height from the floor (m) in the case of the picking activity. The higher vertical height from the floor higher the rest time requirement in the case of the $h_{2}$ parameter, which is the vertical height from the floor $(m)$ in the case of the storing activity.

\section{CONCLUSIONS}

The work-related musculoskeletal disorders and occupational heat strain problems for workers are investigated in this paper in the case of a typical production line supply process. A new mathematical model is introduced by considering the preventing ergonomic risks associated with the excessive metabolic cost and heat stress. As most kinds of research topics have focused on the human energy expenditure as an ergonomic aspect, our model integrated for the first time the thermal work limit, the rest allowance, and the metabolic cost as ergonomic aspect. The extended new model integrated the rest allowance time to decrease the ergonomic risk. The rest allowance is determined by the metabolic cost and the heat strain, which is based on the handled weight and number of the items. The rest time is the time necessary for preventing fatigue risk associated with load values higher than the optimal lot size. The new model aimed to minimise both the total cost of the production line supply process and the ergonomic risks. The case study based on our developed model presented in this paper investigated the supplying of one type of raw material with one operator to the production line as a so-called "Single Material - Single Operator" (SMSO) model. The analysis results have shown that the new model increases productivity and decrease the ergonomic risk related to heat stress and metabolic cost of the worker. The developed mathematical model can support the decision-making in the planning of the production logistics, where intensive manual material handling activities must be realised. It will decrease high costs associated with work-related musculoskeletal disorders and heat-related illnesses such as absenteeism, heatstroke, heat exhaustion, heat cramps, heat syncope, heat rash, rhabdomyolysis, lost productivity, and increased health care, disability, and worker's compensation costs. The developed approach can help the managers to evluate lot sizes depending on the vertical height of the movement from the floor $\left(h_{1}, h_{2}\right)$ in the case of the picking and storing motions which help to prevent the ergonomic risk. Our model can also help the managers with the decision-making in the workrest time schedule. The results of this study have demonstrated the viability of the lot sizing model optimisation with multiple objectives and complex constraints with regard to the metabolic cost and heat strain. Using the above-mentioned aspects, it has also accommodated the social and economic sustainability in the production line supply.

When it comes to further research direction, it can be said that the investigation of the extension possibilities of the proposed new model with different motions such as pushing and pulling would be very useful. In this way, the further connected physical logistics activities would also be examinable and would become integrable into the core line supplying activities. Another direction can be the improvement of the model with the rest allowance for light work and an extension of the model for the moderate, heavy, and very heavy works that would be a valuable extension of this research. The basic model can also be improved with the 
extension of the number of simultaneously handled materials and the extension of the number of the applied logistics operators to investigate the effects of the ergonomic aspects on this kind of complex system.

\section{SEZEN KORKULU, M.A. ${ }^{1}$}

(Sorumlu yazar)

E-mail: sezen.korkulu@logisztika.bme.hu

KRISZTIÁN BÓNA, Yrd. Doc. Dr. ${ }^{1}$

E-mail: krisztian.bona@logisztika.bme.hu

${ }^{1}$ Malzeme tasima ve lojistik sistemleri departmani,

Budapeste Teknoloji ve Ekonomi Üniversitesi

Bertalan Lajos caddesi 7-9. L binasi, 1111,

Budapeste, Macaristan

\section{ISI STRESİ VE ISŞE BAĞLI KAS-ISSKELET BOZUKLUKLARINI ÖNLEMEK IÇİN PARTI BÜYÜKL ÜĞ̈ MODELINIIN GELISTTIRILLESI}

\section{ÖZET}

Isl stresi ve metabolik maliyetin yönetimi, işle ilgili herhangi bir rahatsızlı̆̆ önlemek için hayati önem taşır. Bu makalede, islya maruz kalma ve işle ilgili kas-iskelet bozukluklarını önlemek için yeni bir siparis boyutlandırma modeli geliştirmek için isl gerilimi ve metabolik maliyet için dinlenme zamanı formülasyonları entegre edildi. Isı gerinimi ve dinlenme payının üretim tedarik sürecinin toplam maliyeti üzerindeki etkileri araştırıld . Bu çalışmada incelenen problem, bir üretim alanına yerleştirilen bir üretim hattının malzeme ihtiyacını karşılamak için kutulara yerleștirilen hammaddelerin el ile taşınmasıdır. Hammadde deposu ile üretim hattı arasındaki malzeme taşima işlemlerinin gerçekleştirilmesi için Elektrikli Palet Jack (EPJ) kullanılacaktır. Çalışma, bu malzemelerin elle taşınmast için toplama, depolama ve taşıma hareketlerinin araştırılmasını kapsamaktadır. Analiz sonucu, ISO 7243 maksimum metabolik iş limiti ile üretim hattı tedarik sürecinin bu bölümünün toplam maliyetine klyasla isl gerilimi ve dinlenme süresi kullanılarak\% \%,5 tasarruf sağlandı̆̆ını göstermiştir. Sonuç olarak, analiz sonuçlarl geliștirilen yöntemin metabolik maliyet ve usl gerilimi ile ilgili olarak çoklu hedefler ve karmaşık kısıtlamalar ile siparis boyutlandırma modeli optimizasyonunun uygulanabilirliğini göstermiştir.

\section{ANAHTAR KELIMELER}

ergonomi; elle malzeme tasima; metabolik maliyet; iş isi stresi; dinlenme zamani.

\section{REFERENCES}

[1] Cheng Y, et al. Optimal production lot sizing when demand is proportional to stock and backorder levels. International Journal of Industrial Engineering. 2018;25(2): 137-155.

[2] Cunha ARL, et al. Economic production quantity
(EPQ) model with partial backordering and a discount for imperfect quality batches. International Journal of Production Research. 2018;56(18): 6279-6293. DOI: 10.1080/00207543.2018.1445878

[3] Tian G, et al. A multi-objective supplier selection and order allocation through incremental discount in a fuzzy environment. Journal of Intelligent \& Fuzzy Systems. 2019;37: 1435-1455. DOI: 10.3233/JIFS-182843

[4] Tiwari S, et al. Sustainable inventory management with deteriorating and imperfect quality items considering carbon emission. Journal of Cleaner Production. 2018;192: 281-292. DOI: 10.1016/j.jclepro.2018.04.261

[5] Wangsa DI, et al. An integrated vendor-buyer inventory model with transportation cost and stochastic demand. International Journal of Systems Science: Operations \& Logistics. 2018;5(4): 295-309. DOI: 10.1080/23302674.2017.1296601

[6] Zaho QH, et al. Model and algorithm of an inventory problem with the consideration of transportation cost. Computers \& Industrial Engineering. 2014;46(2): 389397. DOI: 10.1016/j.cie.2003.12.019

[7] Andriolo A, et al. A century of evolution from Harris's basic lot size model: Survey and research agenda. International Journal of Production Economics. 2014;155: 16-38. DOI: 10.1016/j.ijpe.2014.01.013

[8] Darom NA, et al. An inventory model of supply chain disruption recovery with safety stock and carbon emission consideration. Journal of Cleaner Production. 2018;197: 1011-1021. DOI: 10.1016/J.JCLEPRO.2018.06.246

[9] Gholamian RM, et al. Inventory control of obsolete products with price-dependent demand. Journal of Engineering Research. 2020;8(4): 169-184. DOI: 10.36909/jer. v8i4.8316

[10] Rezaei J. Economic order quantity for growing items. International Journal of Production Economics. 2014;155: 109-113. DOI: 10.1016/j.ijpe.2013.11.026

[11] Korkulu S, et al. Ergonomics as a social component of sustainable lot-sizing: A review. Periodica Polytechnica Social and Management Sciences. 2019;27(1): 1-8. DOI: 10.3311/PPso. 12286

[12] Al-Araidah O, et al. A Monte Carlo simulation to estimate fatigue allowance for female order pickers in high traffic manual picking systems. International Journal of Production Research. 2020;59(1): 1-12. DOI: 10.1080/00207543.2020.1770357

[13] Andriolo A, et al. A new bi-objective approach for including ergonomic principles into EOQ model. International Journal of Production Research. 2016;54(9): 2610-2627. DOI: $10.1080 / 00207543.2015 .1113324$

[14] Battini D, et al. New methodological framework to improve productivity and ergonomics in assembly system design. International Journal of Industrial Ergonomics. 2011;41(1): 30-42. DOI: 10.1016/j.ergon.2010.12.001

[15] Battini D, et al. Linking human availability and ergonomics parameters in order-picking systems. IFAC-PapersOnLine. 2015;48(3): 345-350. DOI: 10.1016/j.ifacol.2015.06.105

[16] Battini D, et al. Ergo-Lot-Sizing: Considering ergonomics in lot-sizing decisions. IFAC-PapersOnline. 2015;48(3): 326-331. DOI: 10.1016/J.IFACOL.2015.06.102

[17] Battini D, et al. The integrated assembly line balancing 
and parts feeding problem with ergonomics considerations. IFAC-PapersOnLine. 2016;49(12): 191-196. DOI: 10.1016/j.ifacol.2016.07.594

[18] Battini D, et al. Ergonomics in assembly line balancing based on energy expenditure: A multi-objective model. International Journal of Production Research. 2016;54(3): 824-845. DOI: 10.1080/00207543.2015.1074299

[19] Battini D, et al. Ergo-lot-sizing: An approach to integrate ergonomic and economic objectives in manual materials handling. International Journal of Production Economics, 2017;185: 230-239. DOI: 10.1016/j.ijpe.2017.01.010

[20] Botti L, et al. Integrating ergonomics and lean manufacturing principles in a hybrid assembly line. Computers \& Industrial Engineering. 2017;111: 481-491. DOI: 10.1016/j.cie.2017.05.011

[21] Finco S, et al. Heuristic methods to consider rest allowance into assembly balancing problem. IFAC-PapersOnLine. 2018;51(11): 669-674. DOI: 10.1016/j.ifacol.2019.11.473

[22] Finco S, et al. Workers' rest allowance and smoothing of the workload in assembly lines. International Journal of Production Research. 2020;58(4): 1255-1270. DOI: 10.1080/00207543.2019.1616847

[23] Finco S, et al. A bi-objective model to include workers' vibration exposure in assembly line design. International Journal of Production Research. 2020. p. 4017-4032. DOI: $10.1080 / 00207543.2020 .1756512$

[24] Gholamian MR, et al. A sustainable inventory model by considering environmental ergonomics and environmental pollution, case study: Pulp and paper mills. Journal of Cleaner Production. 2018;199: 444-458. DOI: 10.1016/j. jclepro.2018.07.175

[25] Tang Q, et al. Ergonomic risk and cycle time minimization for the U-shaped worker assignment assembly line balancing problem: A multi-objective approach. Computers and Operations Research. 2020;118: 104905. DOI: 10.1016/j. cor.2020.104905

[26] Bernard TE, et al. Short-term heat stress exposure limits based on wet bulb globe temperature adjusted for clothing and metabolic rate. Journal of Occupational and Environmental Hygiene. 2009;6(10): 632-638. DOI: $10.1080 / 15459620903133642$

[27] Chan APC, et al. Using the Thermal Work Limit as an Environmental Determinant of Heat Stress for Construction Workers. Journal of Management in Engineering, 2013;29(4): 414-423. DOI: 10.1061/(ASCE)ME.19435479.0000162

[28] OSHA 2017. OSHA Technical Manual. Chapter 4: Health hazards-heat stress. Available at: https://www.osha.gov/ dts/osta/otm/otm_iii/otm_iii_4.html

[29] ILO 2015. Global trends on occupational accidents and diseases. Available at: https://www.ilo.org/legacy/english/
osh/en/story_content/external_files/fs_st_1-ILO_5_en.pdf

[30] EU-OSHA 2017. An international comparison of the cost of work-related accidents and illnesses. Available at: https://osha.europa.eu/en/tools-and-publications/publications/international-comparison-cost-work-related-accidents-and/view [Accessed 8 May 2019].

[31] Bevan S. Economic impact of musculoskeletal disorders (MSDs) on work in Europe. Best Practice \& Research Clinical Rheumatology. 2015;29(3): 356-373. DOI: 10.1016/j.berh.2015.08.002

[32] Price AD. Calculating relaxation allowances for construction operatives - Part 1: Metabolic cost. Applied Ergonomics. 1990;21(4): 311-317. DOI: 10.1016/00036870(90)90202-9

[33] Rowlinson S, et al. Application of the predicted heat strain model in development of localized, threshold-based heat stress management guidelines for the construction industry. Annals of Occupational Hygiene. 2014;58(3): 326339. DOI: 10.1093/annhyg/met070

[34] Brake DJ, et al. Limiting metabolic rate (thermal work limit) as an index of thermal stress. Applied Occupational and Environmental Hygiene. 2002;17(3): 176-186. DOI: $10.1080 / 104732202753438261$

[35] Garg A, et al. Prediction of metabolic rates for manual materials handling jobs. The American Industrial Hygiene Association Journal. 1978;39(8): 661-674. DOI: $10.1080 / 0002889778507831$

[36] Digiesi S, et al. Sustainable Inventory Management. In: New Models for Sustainable Logistics. SpringerBriefs in Operations Management. Springer; 2016. DOI: 10.1007/978-3-319-19710-4

[37] ISO 7243. Hot Environments - Estimation of the heat stress on working man, based on the WBGT-index (wet bulb globe temperature). Geneva: International Standard Organisation; 1989.

[38] Miller VS, et al. The thermal work limit is a simple reliable heat index for the protection of workers in thermally stressful environments. Annals of Occupational Hygiene. 2007;51(6); 553-561. DOI: 10.1093/annhyg/mem035

[39] Brake DJ, et al. A valid method for comparing rational and empirical heat stress indices. Annal of Occupational Hygiene. 2002;46(2): 165-74. DOI: 10.1093/annhyg/mef030

[40] ISO 8996. Ergonomics of the thermal environment. Determination of metabolic rate. Geneva: International standards Organisation; 2004.

[41] Barta Z, et al. Development of AIM method planning of inbound material handling processes. Acta Technica Jaurinensis Series Logistica. 2010;3(3): 285-299. Available at: https://acta.sze.hu/index.php/acta/article/view/79

[42] ISO 80000-5. Quantities and units -- Part 5: Thermodynamics. 2007. 